\title{
The Administrative Empowerment and its Relationship with the Innovative Behavior among the Head / Coordinators of the Academic Department at the Faculty of Science and Arts, Sharurah - Najran University
}

\author{
Mohammad Qasim AL- Magableh (Corresponding author) \\ Assistant professor in the Faculty of Science and Arts, Sharurah \\ Najran University, Kingdom of Saudi Arabia \\ E-mail: dr_mohammed_magableh@yahoo.com
}

Abedalqader Mohammed Otoum

Lecturer in the Faculty of Science and Arts, Sharurah

Najran University, Kingdom of Saudi Arabia

E-mail: atoum_abdo@yahoo.com

Received: July 6, 2014 Accepted: August 18, 2014 Published: September 11, 2014

doi:10.5296/ire.v2i2.6298 URL: http://dx.doi.org/10.5296/ire.v2i2.6298

This research is supported by the Deanship of Scientific Research at Najran University Research Code: NU/SHED/13/46

\begin{abstract}
This study aimed to identify the degree of administrative empowerment as well as the degree of the innovative behavior among the head/ coordinators of the academic department at the Science and Art Faculty in Sharurah from the faculty members' perspective during the academic Year 1434- $1435 \mathrm{H}$. It points out if there is correlation between the administrative empowerment and the innovative behavior according to the study variables: gender, major, teaching experience, and academic rank to achieve the objectives of the study.
\end{abstract}


Two questionnaires were designed to collect data, the first is used to measure the degree of the administrative empowerment among the head/ coordinators of the academic department at the Science and Art Faculty, while the second is used to measure the degree of the innovative behavior among the academic coordinators at the Faculty of Science and Art .The study sample involves (120) male faculty members and (44) female faculty members who were selected randomly from different human and scientific departments at the Faculty of Science and Arts in Sharurah. To answer the questions of the study, the two researchers develop the first questionnaire, which is divided into two parts. The first part is concerned with the personal data, while the second part relates to the administrative empowerment, which contains (45), items distributed on four domains: the administrative work, authority of delegation, self-motivation, communications and human relations. Meanwhile the second questionnaire is, developed by researchers, having (47) items distributed on five domains: mental characteristics, emotional characteristics, innovation and originality, teamwork and simulation

The study shows that head/ coordinators of the academic department at the Faculty of Science and Arts have a medium degree of administrative empowerment and a medium degree of innovative behavior alike. It also indicates that there is a positive correlation, which has statistical significance between the degree of administrative empowerment among the head/ coordinators of the academic department and their innovative behavior.

At the light of this study, the two researchers recommended holding training courses related to the administrative operations among academic coordinators based on efficiency and opportunity equality. The study also recommends selecting the academic Heads / coordinators from those who have innovative leaders and believe in innovation and tendency to take risks.

Keywords: Administrative Empowerment, Innovative Behavior, Faculty of Science and Arts, Sharurah, Najran University, Kingdom of Saudi Arabia

\section{Introduction}

Human resources are considered the most important asset of the organization, which should be exploited efficiently. Employee empowerment practically proves that it leads to improving the performance and productivity, employees, clients' satisfaction, and the increase the organizational effectiveness (Ahmad \& Sayed, 2011). That is why we see that empowerment works to liberate the leader of the routine, encouraged, and stimulated him by the practice of Initiative and innovation, and this is done by participating and contributing to the decision-making, responsibility and belonging. Empowerment is viewed as one of the modern methods for the management of human resources to exploit the potential capabilities of leadership and self-motivation and the ability of innovation and innovation, and to achieve the objectives of the organization efficiently and effectively.

Ibrahim \& others (2008: 13) point out that the subject of administrative empowerment is considered as one of the modern subjects, and interest to many researchers in order to establish the principle of innovation at work among workers in the field of management, and the cry that echoes recently in the field of management thought, which cares for the 
development of the human side within the institution.

Ali (2007) assures that the empowerments of workers takes several phases and achieved in several ways including authority of delegation, motivating employees, designing functions in a way to enable workers to employ their innovation, and were linked to the element of mutual trust between superiors and subordinates.

Shoush (2011) pointed to the contribution of the innovative behavior of employees in achieving competitive advantage, and increasing the organization's ability to survive and adapt, and that the innovative behavior of employees have a positive impact on performance indicators, productivity, due to the role of the innovative behavior of employees.

Milham (2009) defined the empowerment as "an internal state of mind that needs to embrace and represent this situation by the individual in order to have self-confidence and satisfaction with thee abilities he has to help him in taking decisions and testing the results that would be up to it."

"Administrative Empowerment is an organizational strategy, and a new skill designed to give workers the authorities, responsibilities, and give them the freedom to perform the work in their own way without the direct intervention of the administration, while providing all the resources, and appropriate working environment for rehabilitation professionally and behaviorally to perform the work with full confidence in them" Ta'ani (2011: 205).

The Word 'concept of innovation' in the Arabic language is from the verb "innovate" i.e. "to innovate something, which means to a non-existing thing. In the English language the word "Innovate" means "to find something new", but the origin of the word innovation Latin word "Novus" which means "New", Aleut and Mghebre (2013).

Rasool and Elnour (2012) see that innovation is a behavior that makes something that was not there before, others added that innovation behavior that makes a new thing that has properties of novelty and appropriate and the economy.

Al-Shqran and Ababneh (2013) assure in a study that the most educational institutions have focused to apply the concept of administrative innovation within its various departments, and worked to spread the culture of focusing on the importance of innovation, transparency and efficiency and excellence, decentralization and delegation of authority and the use of information technology.

Badh and Abu Taha (2013: 450) tried to develop the basic skills of innovation, which must be within the ability leader, including a sense of the problems and administration, fluency, originality, Flexibility, and continue the trend towards goal.

Qassimi (2002) pointed out that the administrative innovation mostly includes finding the development and improvement in administration systems or in the plans, programs, procedures, and rules of administrative work to be different from what it was, and lead to positive results, directly or indirectly, to the administrative work and the services they provide to the public. 
Alsakarneh (2011) claimed that the innovative behavior is conduct or behavior practiced by an individual or group in the workplace and the relationship between administrational behavior and the innovation behavior is considered relevant to a certain extent. Because the provision of a suitable environment for employees, and giving them confidence as well as the ease of communication and the speed of decision-making, and acceptance of the innovate change, all this affects the innovative behavior of the individual within the organization.

Qaryouti (2000) mentioned that an innovation administrator is considered oppose the traditional notions held by the majority of people who hate change, and prefer to continue on what they are in their different work. The innovator in the field of administration is often someone who likes risk, and seeks to know the unknown, trying to think of new ways to work and is characterized by the ability to visualize several alternatives for dealing with the problems, self-confidence, the ability to adapt, and experiment, innovation, the courage to express opinions, and proposals, individual independency .

Harem (1997: 463-484 )pointed out that Evan sees innovation as a response to environmental changes, or away to make change to the organization, he defined the organizational innovation as: the application of the idea developed within the organization, or has been borrowed from outside the organization, whether related to the product, or the means, or the program or service, which is a new idea for the organization when applied, also he sees that innovation is to look at phenomena, things and problems with a different view that interacts with the individual work, an environment of the organization, the individual research, survey or intuition, and link objects, leading to the new production, original, valuable production to the individual and society.

Robey (1991) looked to the innovation process from the perspective of the organization, and he describes the innovation process as a phase involves feeling the need, and the productivity stage where ideas are generated to solve problems, and the application stage, where the stage of productivity make a decision to apply innovation given, and continue the implementation phase until making innovation which was accepted as part of the daily routine, and the final acceptance innovation often face complex problems because many of the problems occur during the application, which is not expected at the stage of proactive.

Kreitner and Kinicki (1992) pointed out that the characteristics of innovate personality are: knowledge, learning, intelligence, and strength of character, and social customs, the innovator to interact and exchange views with others, and is characterized by a spirit of risk and independence, and persistence, and motivation, and openness to new ideas, and tolerance.

The innovation is limited to the very smart people, and innovation is not restricted only to individuals, but it can be a collective or institutional. Agila and Ben Noy (2007: 163_179).

"Innovate managers should be innovative in their ideas and methods, and to have an administrative motivational tolerance so that workers can carry out innovation, and continue to support and attract elements of the innovation" Alsakarneh (2011: 135).

Al Qassimi (2002) sees that the administrative innovation is ideas and practices provided by the managers and workers, which requires finding the administrative processes and methods 
and more efficient and effective techniques to achieve the objectives of companies, institutions and departments, and find more services to the community.

Me'mar (2003: 163) mentioned that the Innovation is "the fruit of considering the familiar things in a non-familiar way through the use of the correlations that arise in mind to meet the personal need, or innovate, and to achieve goals, solve problems arising from exciting, and excitement, or reinforcement, motivation, or perception, and intuition".

The studies suggest that indicators of administration innovation in the enterprise are determined by the nature of the cooperation through an integrated team, and the existence of committees, in addition to having the attributes of employees represented as follows: the risk, determination, counseling, advise others, administration conflict, and stimulating work environment (AL Owaisi, 2007).

By looking at innovation, it can be said that it is the proficiency in doing work, innovation is not just to improve the work, but also the contribution to develop toward the better, add something new, and the use of new concepts like innovation which means finding something unfamiliar, or inventing a new idea, or a compilation of ideas, information, methods of noninterconnected, and converted to a new idea, or a new product. We notes from that the essence of innovation lies in the ideas that created only by humans, and these innovate ideas and new knowledge are considered to be the basic reason for the development and progress of societies, and the progress and growth depend mainly on the innovation because the way of progress cannot be achieved by speeches and talk, but by a innovate administration. In addition, every organization has a human element, so it must have their own ideas, and aspirations, distant targets, aspirations, and hopes trying to achieve.

\section{Review of Related Literatures}

\subsection{The Studies Related to Administrative Empowerment}

The study of Hamouri and Saoud (2010) which aimed to determine the degree of career empowerment for academic leaders in the official Jordanian universities, and its relationship with achievement motivation they have. The study results indicated that the academic leaders at public universities enjoy moderately, and enjoy a large degree of motivation, and that there is a statistically significant positive relation between the degree of empowerment and the level of career motivation achievement among academic leaders in the official Jordanian universities.

A study by Lau (2010) which aimed to explore the relationship between administrative empowerment and organizational outputs such as innovation, effectiveness, and good performance. The study pointed out that the non-academic staff in higher education are responsible for the operational work at the university, and organizational strategies administrative empowerment, which encourages initiatives and innovations, and innovative behavior and working to stay longer period of time for colleges and universities. The study pointed out that the non- academics staff in higher education fined low care by academics. 
While the study of Ta'ani (2011) which aimed to identify the degree of administrative empowerment for public schools managers in the province of Karak. The study sample consisted of 166 directors. The result of the study showed that all dimensions of administrative empowerment have got high means, as well as the lack of significant statistical differences in the estimates of the respondents to the degree of administrative empowerment due to the type variable, and qualification, and the interaction between them, as the results showed the existence of differences in the degree of administrative empowerment attributed to the experience for the benefit of the experience of 11 years or more.

The study carried out by the Shousha (2011) which aimed to test the impact of the empowerment of employees on their innovative behavior, and the study found the presence of positive impact of the psychological empowerment on the innovative behavior of employees, the results also showed the presence of a moral positive impact to the organizational empowerment on the innovative behavior.

With regard to the study carried out by Al-Mohtaseb (2011) which aimed to identify the administrative empowerment, and its impact on productivity among workers at the University of Al-Hussein Bin Talal, the study found that there is a significant impact with a statistical significance for the administrative empowerment on productivity ( the diversity of skills, abilities, and the diversity of talents, diversity of experience), in addition to that, work teams which have the most empowerment capabilities a high level of job satisfaction and loyalty.

Al Tarawnh and Al Qudah study (2011) aims to recognize the reality of the administrative empowerment of woman at the public Jordan Universities and the organizational, social and personal obstacles, which influenced it. The study reaches to these results: The reality of administrative empowerment of women at public Jordan Universities came to the medium degree and there was an effect for the personal obstacles, the period of the service at the university as well as the interaction between periods of service and academic rank, there are statistical significant differences of the administrative empowerment of woman at public Jordan Universities and a variable of personal obstacle.

A study was done by Omari (2011) aimed to recognize the relationship between recruiting empowerment and the organizational commitment of the academic leaders at King Suad University, the study was applied on (230) personnel and the study comes up with these results: A positive relationship was found between subfields of recruiting empowerment measures (freedom of choice, self-efficiency, meaning of labor, the influence) and the entire degree of the organizational commitment.

AL Shareef (2012) aimed to recognize the nature of administrative empowerment and its dimensions and how can the administrative empowerment raises the competencies of administrative staff at UMM Al Qura University. The researcher used the descriptive analysis method. The most important empowerment results are: improving the level of employees' productivity and increasing the innovation and innovation opportunity while the most important administrative empowerment obstacles are: administrative centralization. 
In a study carried out by Mahasna (2007) which aimed to analyze the impact of administrative empowerment in exploring attributes of work teams. The study found that the perceptions of the respondents to the dimensions of empowerment came moderately, while their perceptions of the delegation of authority is high.

AL Qadi (2009) aimed to identify the estimation of academic leaders in Jordanian universities in the northern region of the degree of their ability to the dimensions of empowerment, and to identify whether there were statistically significant differences in the degree of empowerment among academic leaders in Jordanian universities in the northern region due to the variables: sex, career, type of college, experience, academic rank, and the number of training administrative sessions related to empowerment. The results indicated that the field of training and self-development came in the first in the areas of administrative empowerment, and the field of self-motivation came in the last, and that there are differences between the mean estimates of the sample on the areas of administrative empowerment for sex variable except the field of self-motivation, and the differences were in favor of the estimates of the female, while the study of Sevng, Bum and Sang (2009), which aimed to test the impact of empowerment on the team career. Survey was conducted on (176) government employee, the study revealed that: self-esteem, responsibility, information, and innovation had its significance and positive impact on the team. The study suggested that career empowerment programs must take a number of different dimensions to enable managers to take into account the four dimensions that have addressed in the study, which will help in the design and implementation of a successful empowerment program.

The study carried out by Boundrias et al. (2009) which aimed to test the relationship between administrative empowerment and functional behavior of the supervisors. The results indicated that administrative empowerment for supervisors have a strong relationship with the psychological empowerment, but the relationship is weak in relation to behavioral empowerment, while the study of Al Ibrahim, Adayleh, and Al Omari (2008) which aimed to identify the degree of administrative empowerment among workers at Yarmouk University. The results indicated the presence of statistically significant differences related to the impact of sex and in favor of males, and qualification, and job title, on the degree of practicing administrative empowerment among workers at Yarmouk University.

The study is conducted by Gill et al. (2010), which aimed to test the relationship between transformational leadership, empowerment, career, and social behavior. Ways and means have been applied to workers in factories in Canada, and India to test the relationship between transformational leadership, and career empowerment in the countries for different cultural level, the results indicated that the degree of career empowerment was high with transformational leadership with regard to good treatment, and appreciated by others in those two countries, as well as there were statistical differences between workers in both countries.

Al Qudah and Melhm (2011) study aimed at testing the effect of information in general and information technology in private recruiting empowerment at private schools in the north of Jordan. The study reaches at the following results: There is a critical influence on information technology variables in general affected the recruiting empowerment at private schools and 
there is a statistical significant relationship between empowerment and information technology.

Watanbe (2011) aimed at analyzing the Indian Government Approach in increasing the educational opportunities and let female students participate in using the recruiting empowerment. This study conducted at three schools and interviews were done with teachers and administrative staff. A survey consists of (139) teachers was carried out in the duration of four months of the year 2009 based on ways that are used by the innovative teachers in teaching activities. Interviews were done with those who supervised on the program and coordinators so as to recognize the difficulties that face implementing this program such as : teachers, students, the relationship between them based on guidance as part of the primary education and other big challenges such as: lacking of the female teachers number especially those who teach post 8 th grades and lacking the health insurance.

\subsection{The Studies Related to the Innovative Behavior}

A study of Ababnhn and Shogran (2013) aimed to identify the degree of administrative innovation practice of the educational leaders in the Directorate of Education in Ramtha region for the academic year (2010 --2011). The study sample consists of (223) educational leaders. The study resulted that the degree of the administrative innovate practice of the educational leaders at the Directorates of Education In Irbid region has reached at a medium degree, while Morsi's and Mohammad's study (2012) aimed to identify the relationship between the prevailing organizational culture and the level of the administrative leaders' innovation at Asyoot university. The two researchers used two questionnaires applied on (88) staff members at Asyoot University, resulted that there are innovative leaders available, and have the ability of analysis, flexibility. Fluency, problem sensitivity of the university leaders.

Ashour carried out a study in (2011) aimed to recognize the capabilities of using information technology and communications in developing administrative innovation of educational leaders who are working at the Directorate of Education in Oman, the study reaches that using information technology and communications in developing administrative innovation of educational leaders who are working at the Directorate of education developing administrative innovation of educational leaders at the Directorate of Education with high capabilities which leads to developing administrative innovation to leaders at the directorate of education.

Another study was conducted by Arabiat (2011) about applying administrative innovation on the teaching staff at Princess Muna College at Al Balqa University and at Princess Alia College, the result indicated that there is statistical significant relationship between administrative innovation to the teaching staff at Princess Muna College at Al Balqa University and at Princess Alia College and recruiting performance.

A study was done by Al Otaibi (2010) aimed to recognize the obstacles of administrative innovation of High schools female principals in Jedah and their abilities to be in line with technological progress. In addition, the study shows the elements of administrative innovation such as the personal elements. The study also indicates that there is simple 
differences between means the degrees of female principals who got doctoral degrees and female principals who have bachelor degrees, but the differences don't have any statistical significant. The degree of practicing administrative innovation doesn't relate to the type of majors, but it relates to female principals' ability to deal with modern technology.

There is another study for AL Huweeleh and AL Huweeleh (2009) aimed to detect how was the degree of high school male and female principals' practice and behavior achieve the administrative innovation in ALHamudi region. The study sample consists of all male and female principals (66) as well as another sample consists of (208) male and female teachers. The results of the study show that practicing behaviors to achieve administrative innovation was rated high of the male and female principals perspectives, medium according to male and female teachers perspectives.

A study for Ebdah and Jaghbeer (2008) aimed to recognize the degree of innovation in administrative behavior of school principals and it shows that a medium degree of innovation of primary and high school principals' administrative behavior as well as there is a statistical significant differences in the degree of innovation which was in favor of higher qualifications and short administrative experience, while Abed Alrasool's study (2012) aimed to recognize the reality of administrative innovation and its obstacles of primary school principals in Egypt. The study sample consists of (99) male primary principals and the results were as follows: The most important administrative obstacles are the inconvenient environment for the innovate, job promotion, is irrelevant to innovative acts. No delegation of authority.

Al-Mosa (2011) aimed to identify the internal and external environment conditions. This study was applied on (101) female principals; the results indicate that there is a need to administrative innovative leaders to face all new technological and social efforts that can be affected school environment.

\section{Problem of the Study}

Many of the administrative studies show that organizations remarkably focus on technical innovation more than on administrative innovation in which this leads to the organizational gap and negatively affected to the performance of the organization as a whole (Alsakarnh, 2011: 49).

The Administrative Innovation considers as one of the modern management subjects, which focuses on the management and administrators. The head / Coordinators of the academic departments at universities play prominent and important role in finding Administrative Innovation in their departments and colleges in order to improve and develop the administrative work and services rendered for the students in one hand and society on the other.

We see that innovation is mainly based on the change and bring something new, and for the organization to maintain the survival and continuity it must deliver what is new and unique and thus achieve growth, prosperity and development, and undoubtedly the administrative innovation processes of desired administration is only making the routine administrative things different from what they were. In addition, for this, we find that the administrative 
Innovation seeks for change, development, improvement, and the dimension of the routine to find ways and means and ideas in a better, faster, and the finest ways.

Progressing institutions of higher education depends on humans in general and on academic leaders in specific, so many factors have urged the researchers to be attention to the importance of administrative empowerment and its relationship to innovative behavior.

Moreover, many enormous challenges facing University education, so we need good academic leaders who have ability in developing, changing, knowledge, modern concepts of administration, technology that lead to innovative behavior, on the other hand it will reflect in the quality of teaching in a university.

Both researchers found that necessary to deal with the subject of administrative empowerment and its relationship with innovative behavior of the Head/coordinator of the academic department in order to know the demands of administrative empowerment as it is significant in developing faculty members to release their latent innovate energies.

The problem of this study could be concluded in the following question:

Is there a relationship between Administrative Empowerment and the Innovative Behavior among the Head/ Coordinators of the Academic Department at the Faculty of Science and Arts, Sharurah - Najran University?

\section{Objectives of the Study}

This study aims to:

- To identify the degree of administrative empowerment of the Head / coordinator of the academic department at the Faculty of Science and Arts in Sharurah - Najran University, from the faculty members' perspective.

- To identify the degree of innovative behavior of the Head/Academic members' perspective at Science and Art Faculty in Sharurah- Najran University, from the faculty members' point of view.

- To identify whether there is a correlation between administrative empowerment and innovative behavior at Faculty sections, which are attributed to gender, major, teaching experience and academic rank, from faculty members' perspective at the Faculty of Science and Arts in Sharurah- Najran University.

\section{Research Questions}

This study attempts to answer the following questions:

1) - What is the degree of the administrative empowerment of the Head/ Academic department Coordinator at the Faculty of Science and Arts in Sharurah -Najran University from the Faculty member's perspective? 
2) - What is the degree of the innovative behavior of the Head/Academic department Coordinator at the Faculty of Science and Arts in Sharurah -Najran University, from Faculty members' perspective?

3) - Is there any correlation which has statistical significant at level $(0,05)$ between administrative empowerment and innovative behavior in the Academic department can be attributed to the variables of : gender, major, teaching experience and academic rank from the faculty members' perspective at the Faculty of Science and Arts in Sharurah-Najran University?

\section{Procedural Terminology and Definitions}

Administrative Empowerment is defined as giving the employees a wide space of freedom inside the organization in decision making process through expanding the mandate of delegation the authority, increase in participating, self-motivation, the importance of teamwork, and developing their innovative behavior (Al Mahasneh, 2007: 13).

The two researchers define administrative empowerment procedurally as one of the modern administrative styles in the field of human resources management and a source of energy for employees (faculty members). And also it aims at giving full authority and responsibility for faculty members through delegation of authority and providing all kinds of incentives so as to award distinguished performance, offering occupational opportunities, focusing on teamwork and innovative ideas and thoughts as well as creating a stimulating environment for faculty members.

Innovative behavior: It is defined as:" a behavior and a distinguished conduct which is practiced by the individual or a group in the workplace and it is not necessary to produce services or new products. As well as it is at the end a behavior precedes the innovation . The behavior can be innovative experienced for the first time by the individual" (Al Salim, 1987: 40).

The two researchers defined the innovative behavior as a behavior or conduct of the Head/coordinator of the academic department that can be recognized by its characteristics: mentality, emotions and a belief in the importance of teamwork.

\section{Limitations of the Study}

Human limits, the nature of study society, faculty members at the Faculty of Science and Arts in Sharurah- Najran University. Males and females in various humanity, scientific major.

Location Limits: The Faculty of Science and Arts in Sharurah - Najran University -Kingdom of Saudi Arabia.

Time limits: the academic year for the first semester 1434 - $1435 \mathrm{H}$.

\section{Methodology and Procedures of the Study}

The two researchers used the descriptive analytical approach in which they include the theoretical literature related to the subject of the study. They wrote the theoretical framework 
related to previous related to the administrative empowerment and the innovative behavior and its objectives and effects, discussed the previous related studies and developed a tool for the study (Two Questionnaires) that include two parts:

The first one contains personal data while the other is related to the administrative empowerment and the innovative behavior. The two questionnaires were checked by its reliability and validity and certified by a sample of experts and then the two questionnaires were applied on the study sample.After that data were analyzed by using (SPSS) program. The results were discussed, analyzed and interrupted.

\subsection{The Population of the Study}

The study consists of all female and male faculty members at the Faculty of Science and Arts in Sharurah - Najran University in the department of humanities and science specialties. The total number of the study society is (140) male and female faculty members for the academic year 1434-1435 H.

\subsection{The Study Sample}

The study includes 102 faculty members, (58) males and (44) females and were randomly selected from the study society, Table 1 shows the distribution of the sample members according to independent variables.

Table 1. Frequencies and Percentiles according to study variables

\begin{tabular}{|c|c|c|c|}
\hline Variables & Categories & Frequencies & Percent \\
\hline \multirow{2}{*}{ Gender } & Male & 58 & 56.9 \\
\hline & Female & 44 & 43.1 \\
\hline \multirow{2}{*}{ major } & Humanity & 56 & 54.9 \\
\hline & Scientific & 46 & 45.1 \\
\hline \multirow{3}{*}{ Experience } & $1-5$ & 54 & 52.9 \\
\hline & $6-10$ & 34 & 33.3 \\
\hline & More than 10 & 14 & 13.7 \\
\hline \multirow{4}{*}{ Academic rank } & $\begin{array}{l}\text { Associate } \\
\text { professor }\end{array}$ & 4 & 3.9 \\
\hline & $\begin{array}{l}\text { Assistant } \\
\text { professor }\end{array}$ & 60 & 58.8 \\
\hline & Lecturer & 38 & 37.3 \\
\hline & Total & 102 & 100.0 \\
\hline
\end{tabular}

To measure the degree of administrative empowerment and innovative behavior the two researchers develop two questionnaires for this study depending on the theoretical literature and the previous studies that are in relation with the administrative empowerment and innovative behavior. Among these studies: the study of (Alabrahim, Aladialah, \& Alomary, 2008; Algade, 2009), and this study was done by the two researchers to know the degree of 
administrative empowerment of the head/coordinators department at the Faculty of Science and Arts in Sharurah- Najran University. The first questionnaire consists of two parts; the first, the personal data of the academic staff. The second in relation with the administrative empowerment in four domains: the administrative work that consists of 14 items. The authority of delegation consists of 10 items. Self-motivation consists of 11 items. The communication and human relationships consist of 10 items. The two researchers follow the rating scale to design the tool according to five rating scale. They put in front of each item a rating scale out of five degrees as they ask the members of the study to choose the best alternative as they use the $\operatorname{sign}(\mathrm{x})$ in the place that represents the level of the acceptance of those who are agree with administrative empowerment. The second questionnaire that is about the innovative behavior in addition to this study that was done by the two researchers to know the innovative behavior of the head /coordinator department at the Faculty of Science and Arts in Sharurah- Najran University. It consists of items in relation with innovative behavior in five domains: the mental characteristics ( 7 items), the domain of imitation and effectiveness ( 8 items), and the emotional characteristics ( 8 items), the domain of innovation and originality (12 items), the domain of group work (10 items). The two researchers put in front of each item a rating scale out of five degrees as they ask the members of the study to choose the best alternative as they use the $\operatorname{sign}(\mathrm{x})$ in the place that represents the level of the acceptance of those who are agree with administrative empowerment.

To be sure, about the tool reliability, they compute the internal consistency on an $\mathrm{n}$ exploratory sample out of the study sample. Its number is 15 according to the equation of Cronbakh. As explained in the table below.

Table 2. Coefficient of internal consistency of Cronbakh Alfa

\begin{tabular}{lc}
\hline Domains - administrative empowerment & Internal consistency \\
\hline 1- administrative work & .84 \\
2- delegation of authority & .79 \\
.3- self motivation & .90 \\
4- communication and human relationship & .85 \\
Total & .95 \\
\hline Domains - innovation behavior & \\
\hline 1- mental charestarestics & .82 \\
2- emotional charestarestics & .84 \\
3- originality and creativity & .80 \\
4- team work & .86 \\
5- imitation & .57 \\
Total & .950 \\
\hline
\end{tabular}




\section{Findings}

Research Question 1: "What is the degree of the administrative empowerment of the Head/ Academic department Coordinator at the Faculty of Science and Arts in Sharurah-Najran University From the Faculty member's perspective?"

To answer this question, they compute the means standard deviation of the degree of the administrative empowerment of the head /coordinator department from the staff points of view as explained the following table:

Table 3. The means and Standard deviations for the administrative empowerment

\begin{tabular}{cclcc}
\hline Rank & number & \multicolumn{1}{c}{ Domains } & Means & Standard deviations \\
\hline 1 & 4 & communication and human relationship & 3.85 & .821 \\
2 & 2 & delegation of authority & 3.82 & .701 \\
3 & 1 & administrative work & 3.73 & .679 \\
4 & 3 & self motivation & 3.53 & .870 \\
& & Total & 3.73 & .692 \\
\hline
\end{tabular}

Table (3) explains that the means are between (3.53-3.85), the domain of the communication and human relationships in the first stage with the highest mean (3.85), whereas the domain of the inside motivation comes at the last stage with mean (3.53), and the mean of the administrative empowerment as all is (3.73).

Research Question 2: "What is the degree of the innovative behavior of the Head/Academic department Coordinator at the Faculty of Science and Arts in Sharurah-Najran University, from Faculty members' perspective?"

To answer the question they compute the means and standard deviation for the degree of the innovative behavior of the head/ coordinator department from the views of the staff as explained in the following table:

Table 4. The means and Standard deviations for the innovative behavior

\begin{tabular}{cclcc}
\hline Rank & number & \multicolumn{1}{c}{ Domains } & Means & Standard deviations \\
\hline 1 & 2 & emotional charestarestics & 3.82 & .787 \\
2 & 4 & team work & 3.80 & .855 \\
3 & 3 & Originality and creativity & 3.65 & .656 \\
4 & 1 & mental charestarestics & 3.52 & .749 \\
5 & 5 & Imitation & 3.38 & .597 \\
& & Total & 3.64 & .660 \\
\hline
\end{tabular}




\section{Macrothink Minstitute"m}

Table (4) explains that the means are between (3.38-3.82) as the domain of the emotional characteristics comes at the first stage with (3.82) whereas the imitation comes at the last with (3.38) and the means of the innovative behavior as all (3.64).

Research Question 3: "Is there any correlation which has statistical significant at level $(0,05)$ between administrative empowerment and innovative behavior in the Academic department can be attributed to the variables of: gender, major, teaching experience and academic rank from the Faculty members' perspective at the Faculty of Science and Arts in Sharurah-Najran University?"

To answer this question they compute Birson's correlation coefficient between the administrative empowerment and the innovative behavior in the academic departments as explained in table (5).

Table 5. Person correlation coefficient of relationship between administrative empowerment and innovative behavior

\begin{tabular}{|c|c|c|c|c|c|c|c|}
\hline Domains & & $\begin{array}{c}\text { mental } \\
\text { charestarestics }\end{array}$ & $\begin{array}{c}\text { emotional } \\
\text { charestarestics }\end{array}$ & $\begin{array}{l}\text { Originality } \\
\text { and } \\
\text { creativity }\end{array}$ & $\begin{array}{l}\text { Team } \\
\text { work }\end{array}$ & Imitation & Total \\
\hline \multirow{3}{*}{$\begin{array}{l}\text { 1-administrative } \\
\text { work }\end{array}$} & $\begin{array}{l}\text { Correlation } \\
\text { cofficient }\end{array}$ & $.772(* *)$ & $.821(* *)$ & $.784(* *)$ & $.809(* *)$ & $.589(* *)$ & $.854(* *)$ \\
\hline & $\begin{array}{l}\text { Statistical } \\
\text { Significant }\end{array}$ & .000 & .000 & .000 & .000 & .000 & .000 \\
\hline & Number & 102 & 102 & 102 & 102 & 102 & 102 \\
\hline \multirow{3}{*}{$\begin{array}{l}\text { 2-delegation of } \\
\text { authority }\end{array}$} & $\begin{array}{l}\text { Correlation } \\
\text { cofficient }\end{array}$ & $.757(* *)$ & $.715(* *)$ & $.719(* *)$ & $.834(* *)$ & $.540(* *)$ & $.813(* *)$ \\
\hline & $\begin{array}{l}\text { statistical } \\
\text { Significant }\end{array}$ & .000 & .000 & .000 & .000 & .000 & .000 \\
\hline & Number & 102 & 102 & 102 & 102 & 102 & 102 \\
\hline \multirow{3}{*}{ 3- self motivation } & $\begin{array}{l}\text { Correlation } \\
\text { cofficient }\end{array}$ & $.661(* *)$ & $.737(* *)$ & $.779(* *)$ & $.747(* *)$ & $.540(* *)$ & $.785(* *)$ \\
\hline & $\begin{array}{l}\text { statistical } \\
\text { Significant }\end{array}$ & .000 & .000 & .000 & .000 & .000 & .000 \\
\hline & number & 102 & 102 & 102 & 102 & 102 & 102 \\
\hline \multirow{3}{*}{$\begin{array}{l}\text { 4- Communication } \\
\text { and human } \\
\text { relationship }\end{array}$} & $\begin{array}{l}\text { Correlation } \\
\text { cofficient }\end{array}$ & $.836(* *)$ & $.818(* *)$ & $.783(* *)$ & $.900(* *)$ & $.531(* *)$ & $.886(* *)$ \\
\hline & $\begin{array}{l}\text { statistical } \\
\text { Significant }\end{array}$ & .000 & .000 & .000 & .000 & .000 & .000 \\
\hline & number & 102 & 102 & 102 & 102 & 102 & 102 \\
\hline \multirow{3}{*}{ Total } & $\begin{array}{l}\text { Correlation } \\
\text { cofficient }\end{array}$ & $.830(* *)$ & $.854(* *)$ & $.847(* *)$ & $.902(* *)$ & $.608(* *)$ & $.919(* *)$ \\
\hline & $\begin{array}{l}\text { statistical } \\
\text { Significant }\end{array}$ & .000 & .000 & .000 & .000 & .000 & .000 \\
\hline & number & 102 & 102 & 102 & 102 & 102 & 102 \\
\hline
\end{tabular}




\section{Al Macrothink

Table (5) explains that the correlation coefficient between the administrative empowerment was high and positive that the value of the correlation coefficient at (0.919), and that is considered a significant value at the level (0.01), which means that the relationship between the administrative empowerment and administrative innovation is positive and strong, which means also that when the degree of administrative empowerment is increased the degree of the innovative behavior is increased also, and it also explains that all domains of empowerment are in a positive relation with the innovative behavior, which ensures that the availability of the administrative empowerment domains of the head/ coordinator departments in the Faculty of Science and Arts in Sharurah- Najran University causes increase innovative behavior.

First: Gender

Table 6. Person correlation coefficient of relationship between administrative empowerment and innovative behavior according to a gender variable

\begin{tabular}{ccccc}
\hline & & \multirow{2}{*}{ Value Z } & \multicolumn{2}{c}{ Innovative behavior as a total } \\
\cline { 5 - 5 } & & & female & male \\
\hline \multirow{2}{*}{$\begin{array}{c}\text { Administrative empowerment as } \\
\text { a total }\end{array}$} & Coorelation R & 0.073 & $.905(* *)$ & $.920(* *)$ \\
& Statistical significant & & .000 & .000 \\
& number & & 44 & 58 \\
\hline
\end{tabular}

There is no difference in the relationship according to geder.

Second: Major

Table 7. Person correlation coefficient of relationship between administrative empowerment and innovative behavior according to majority

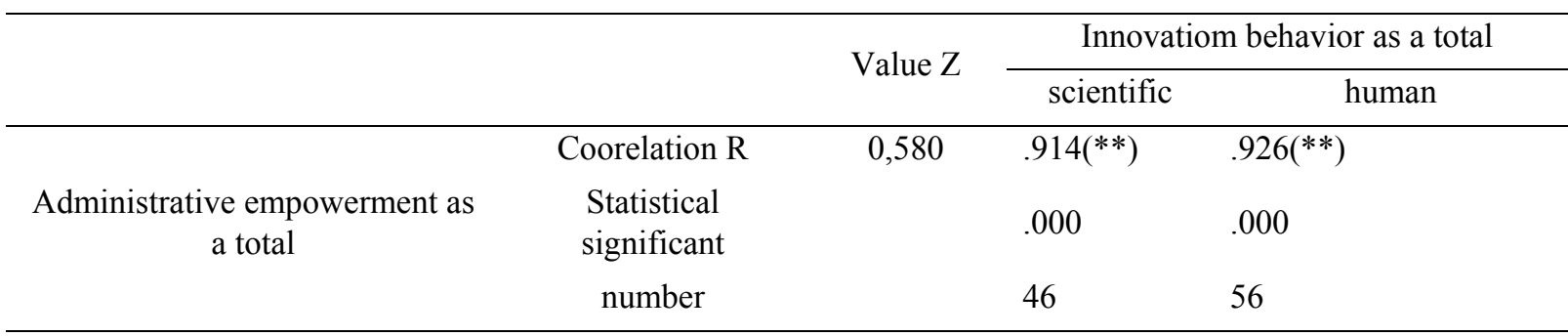

There is no difference in the relationship according to geder. 
Third: Experience

Table 8. Person correlation coefficient of relationship between administrative empowerment and innovative behavior according to experience

\begin{tabular}{|c|c|c|c|c|}
\hline & & \multicolumn{3}{|c|}{ innovative behavior as a total } \\
\hline & & $1-5$ & $6-10$ & More than 10 \\
\hline \multirow{4}{*}{$\begin{array}{l}\text { Administrative } \\
\text { empowerment as a total }\end{array}$} & Coorelation $\mathrm{r}$ & $.938(* *)$ & $.878(* *)$ & $.947(* *)$ \\
\hline & Statistical significant & .000 & .000 & .000 \\
\hline & number & 54 & 34 & 14 \\
\hline & & \multicolumn{3}{|c|}{ value $\mathrm{Z}$} \\
\hline $1-5$ & $6-10$ & \multicolumn{3}{|c|}{0,263} \\
\hline $1-5$ & more than 10 & \multicolumn{3}{|c|}{0,27} \\
\hline $6-10$ & more than 10 & \multicolumn{3}{|c|}{0,197} \\
\hline
\end{tabular}

There is no difference in the relationship according to experience.

Fourth : Academic rank

Table 9. Person correlation coefficient of relationship between administrative empowerment and innovation behavior according to academic rank

\begin{tabular}{|c|c|c|c|c|}
\hline & & \multicolumn{3}{|c|}{ Administrative empowerment } \\
\hline & & $\begin{array}{l}\text { Associate } \\
\text { professor }\end{array}$ & Assistant professor & Lectuerer \\
\hline \multirow[t]{4}{*}{$\begin{array}{l}\text { Administrative } \\
\text { empowerment }\end{array}$} & Correlation $\mathrm{R}$ & $.999(* *)$ & $.912(* *)$ & $.931(* *)$ \\
\hline & $\begin{array}{l}\text { Statistical } \\
\text { significant }\end{array}$ & .000 & .000 & .000 \\
\hline & number & 4 & 60 & 38 \\
\hline & & & \multicolumn{2}{|c|}{ value $\mathrm{Z}$} \\
\hline \multicolumn{2}{|c|}{ Associate professor } & Assistant professor & 0.086 & \\
\hline \multicolumn{2}{|c|}{ Associate professor } & Lectuerer & 0.067 & \\
\hline \multicolumn{2}{|c|}{ Assistant professor } & Lectuerer & 0.088 & \\
\hline
\end{tabular}

There is no difference in the relationship according to acadimic rank.

\section{Discussion}

\subsection{The Results Discussion of the First Question}

The results show that the means of the administrative empowerment of the head / coordinator department in the Faculty of Science and Arts in Sharurah - Najran University are between 
(3.85-3.53), which is considered medium degree in the administrative empowerment of the domain of the study. These results are not agree with( Altaani's, 2011), study results that indicate that the results of all the domains of the administrative empowerment are high, these results are agree with (Alqdah \& Altrawneh, 2011) study that showed to the medium results about the participation of women in the universities of Jordan. The domain of communication and human relationship has the highest mean (3.85), this indicates that there is a satisfaction from the staff in the Faculty toward the head department in comparing with the other domains as it indicates also that there is a human relationship based on respect. this result is agree with (Almahasneh, 2007) study .the domain of the self-motivation has the lowest mean with (3.53) which indicates that the head department has no authority to present incentives of self-development or private facilities in training courses for the member staff. This shows that there is centralization in presenting things. This result agrees with (Alqdi, 2009) study, that shows that the motivation comes at the last rank.

Taking the administrative empowerment domains in details, in the first domain, which is in administrative works, indicates that the head/ coordinator department forms regular meetings for the staff, save the meeting's electronically records, which explains that the head department uses the technical tools, also the head of the department commitment of execution of the lows. Another results show that uses his central reference in making decisions of the department, as he doesn't present any kind of incentives to encourage the distinguished performance. These all indicate that he has no authority to present such kinds of incentives. In the authority of delegation domain, the results show that the head /coordinator department is commitment by the law and the trust of the staff members, which explains that the most of the academic staff has the experience and knowledge, as they are able to do their tasks perfectly. Some items show that the academic staffs are not allowed to share in a cadmic their timetable, which explains their inability to choose the courses they prefer to teach.

In the domain of the self-incentives shows the necessity to encourage the staff member as to accept his innovate initiatives, also explains that the head / coordinator department does not encourage them because this need to be not condemned by routine. Some points also indicate that the professional development is weak, which explains that the head department has no authority to provide them with the private courses and training programs they need. In the communication and human relationship domain, the results show that the way the head department deals with the staff is based on respect and trust. This result is agreed with the result of (Gill et al, 2010), the results show that the degree functional empowerment is high and its relationship with the leadership is positive according to the exchanging respect and trust. This also agree with the study of (Kreitner \& Kiniki, 1994) that shows that the innovate personality leads to interaction and exchanging views, and good relationship with others.

\subsection{The Results Discussion of the Second Question}

The study shows that the means of the innovative behavior of the head /coordinator department are between (3.82_3.38), which is considered a medium degree. This result is agree with the results of (Badeh \& Algaghber, 2008), (Arabiat, 2011), and (Alababneh \& Alshogran, 2013). The results don't agree with the (Alhawleh, 2009) study that shows that 
the degree of the practice of the school heads in Al Ahmadi region in achieving administrative innovation behavior is high from the principals points of view as it is medium from the teachers points of view. The emotional domain has the highest mean degree with (3.82), which indicates that the satisfaction of the staff is also high in compare with the other domains, as it also indicates that the relationship between the members based on the respect, and that there is a good communication as well as the head department is motivated to know the needs of the academic staff. The domain of imitation takes the lowest degree with (3.38), which explains that the head department does not depend on imitate to change the work behaviors, which indicates that there is no importation from the successful examples. This shows the centralization in work from the head department point of view and mistrust towards the others. In The mental domain, the results show that the head department is very smart and has a strong ability to organize the thoughts but at the same time he shows un innovate thoughts and that is what explains his mistrust about the other views or that he is not able to show new ideas because of centralization.

In the emotional domain, the results show that the head department has a high degree of loyalty for the job as he is motivates to achieve his job perfectly. This explains that the most of the staff are experienced and they are able to do what they are asked to do. The results also show that the head department is not able to take the risk because law imposes him and that could be because of his fear from falling or because of the lack of experience. In the domain of originality and innovation, the results show that the head department has the full energy to do his duties. from the other hand, the results show that there is no enough money to accomplish the innovate projects, which explains that the head department has no authority to accomplish them and as a negative result feedback will effect on the academic staff that they don't have to think more or to develop their plans. In the teamwork domain, the results show that the department head encourages the collaborative work between the staff members, which indicates that the exchange respect and trust is the followed style. This explains also that the innovate personality eager to work with the others to exchange views. The results also show that there is no any kind of motivation because of the lack of money, in the domain of imitation, the results show that the department head respect the other ways of work but he does not depend on them to change his negative ways of work. This might be because of his resistance to change and this is a conflict to innovative behavior, which need to exchange and improvement.

\subsection{The Third Question's Answers Discussion}

The Third Question: Is there any correlation which has statistical significant at level $(0,05)$ between administrative empowerment and innovative behavior in the Academic department can be attributed to the variables of: gender, major, teaching experience and academic rank from the Faculty members' perspective at the Faculty of Science and Arts in Sharurah -Najran University?

Table (5) explains that there is a positive relationship between the administrative empowerment and the innovative behavior, which explains that when the head department is able to manage the department, he has an innovative behavior in the domain of work. This 
result is agree with (Alsharif, 2012) study that shows that the most important result of the administrative empowerment is the increasing of labor productivity, and also agree with (Muhammad Morsi, 2012) study that confirmed that the existence of cultural beliefs in a university caused increasing the chances of innovation. Table (6), (7), (8), and (9) explain that there are no differences between the strength of the relationship between the administrative empowerment and the innovative behavior according to: gender, major, experience, and academic rank from the views of the staff members, which explains that there is as strong relationship between them. This result is agree with (Shosha, 2011) study that arrived to the positive effect of psycho empowerment on the innovative behavior of the workers as the positive effect of the organization empowerment on the innovative behavior and the result here confirms that the academic leaders who have the ability to the administrative works and authorize others.

\section{Conclusion}

Administrative empowerment means improving the level of employee's productivity, and increasing the innovation. In addition to giving the employees a wide space of freedom inside the organization in decision making process through expanding the delegation of authority, and providing all kinds of incentives, offering opportunities, focusing on team work, innovative ideas, and creating a stimulating environment for faculty members. One should emphasize again that the administrative innovation considers as one of the modern management subjects. Innovation mainly based on the change and brings something new; achieve growth, prosperity and development. The results showed that there is a positive correlation that has statistical significance between the degree of administrative empowerment among the head / coordinators of the academic department and their innovative behavior.

\section{Recommendations:}

- The necessity of delegation of authority by heads /coordinators to the member's staff in the academic department in the faculty of science and Arts in Sharurah / Najran University.

- The necessity of holding training courses related to the administrative empowerment and innovation to the heads / coordinators to the members staff in the academic department in the Faculty of science and Arts in Sharurah- Najran University.

- The necessity of choosing academic heads/coordinators who believe of the importance of, administrative innovation, and tendency to take risk.

- The necessity acceptance of clear standards accreditation in choosing the academic leaders depending on the efficiency, equal opportunities, and innovation.

\section{References}

Ababneh, R, Mahmoud, \& AL Shqran, R, Ibrahim. (2013). The degree of practicing educational leaders for administrative innovation in directorates of education in Irbid. Journal of Educational and Psychological Sciences, 14(1), 459-486. 
Abed, AL Rasool \& Mahmoud Abou El Nour. (2012). Administrative innovation to a primary school principals in Egypt: Reality - hopefully. Journal of Educational and Social Studies, 18(2), 11-50.

Affendi, A, H (2003). Empowerment workers: the Entrance of improving and continuing development, Cairo, the Arab Organization for Administrative Development.

Agilla, Mohammed Bin \& Nawi Mustafa (2007). Innovation thinking and innovative personal to Organizations: Administrative perspective. Journal of Studies, 6,163-179.

Ahmed, A, Y \& Ibrahim, S (2011). The impact of career empowerment on the organizational innovation by applying on the administrative staff at Teeba University. Journal of Business Research, Zagazig University - Egypt, 33, 423-460.

AL Huweeleh, A., Hadi \& AL Huweeleh, M, Hadi. (2009). Degree of practice secondary schools principals in the educational Al-Ahmadi region for behaviors to achieve administrative innovation. Journal of the Association of Arab Universities, 53, 507-545.

Al Ibrahim, A \& Adayleh, A, \& Al Omari, J (2008). The degree of empowerment among the staff at Yarmouk University. Journal of Education and Social Studies, Egypt, 14(3), 11-39.

AL Mahasneh, M, Abed AL Rahim (2007). The impact of administrative empowerment in the development of the administrative features teamwork, AL Nahdah Journal, 8(1), 127-164.

AL Mohtaseb, A. A. (2011). Administrative empowerment and its impact on the productivity of workers at Hussein Bin Talal University, Egyptian Journal of Commercial Studies, 35(2), 143-169.

AL Mosa, N, Abed Allah. (2011) Developing administrative innovation to the of the Public Schools leaders for girls in Al-Ahsa, Saudi Arabia : a proposed strategic vision, Arabian Gulf Magazine - Saudi Arabia, S 32, 122, 15-100 .

AL Owaisi, R, bin Ali (2007). A culture of administrative innovation in institutions.Tawasol Magazine, Oman, Issue 7, 109104.

AL Qaryouti, Mohammed Qasim. (2000). Organizational Behavior: A study of human behavior in the individual and collective various organizations, third edition, Dar AL Shorooq for publication and distribution_Jordan, 270-330.

AL Qasimi, U, Abed AL Aziz. (2002). The concept of administrative innovation and its developing it, the Third Arab Conference on Management ( innovative leadership in the light of integrity and transparency), Arab Organization for Administrative Development Lebanon, 547-561 .

AL Qodah, M. A. and Tarawneh, N. S. (2011). Reality of administrative empowerment of women at Public Jordanian universities, and affecting constraints it from the point of faculty members, Muotah Journal for Research and Studies, a series of Humanities and Social Sciences, 26(4), 133-178. 
Al Sakarneh, B, Khlaf. (2011). Administrative Innovation (1st ed.). Amman, Jordan Dar AL Maseereh for publishing, printing and distribution, 49-53.

AL Salim, M, Said (1987). Organizational climate, a modern concept in contemporary administrative thought. Arab Journal for administration, 1(11), 37-47.

AL Shareef, M. (2012). Administrative Empowerment and its role in raising the efficiency of workers in universities: an analytical study. Journal of the Faculty of Education Ismailia, 24, 291-312.

Ali, M, Abed Al Azeem (2007). Administration for empowerment workers in sporting institutions and their relationship to Achievement motivation they have, Zagazig University, the Second International Scientific Conference March 21 to 22 Vole 1.

Al-Otaibi, A, Mohammed. (2010). Elements of administrative innovation to the secondary school principals in the area of Jeddah in the light of keeping up the requirements of technological advances from teachers point of view, Arab Journal of Studies in Education and Psychology, 4(4), 211-253.

Alout, Al Batool, \& Magbri, S. (2013). Administrative Innovation and its mechanisms developing it at Zayan University in Gellfa. Journal of Law and Humanities, 13, 227-239.

ALQadi, N (2009). Administrative empowerment among academic leaders at the Jordanian universities in the northern region from their point of view, Journal of the Faculty of Education, Ain Shams University, Issue, 3 Part 2, 625 _ 654

Arabiat, Bashir (2011) .Administrative innovation to the member staff at Princess Alia College in AL Balqa Applied University and its relationship to job performance they have. Journal of the Faculty of Education at Ain Shames University, 3(35), 359-380.

Ashour, M, Ali (2011). The possibility of employing informational technology and communication in developing administrative innovation to educational leaders in directorates of education in Oman. Journal of Education to the University of Kuwait, 26(101), 153-205.

Badeh, A, Mohammed \& Abu Taha, M, Mohammed. (2013) Fundamentals and practicing of administrative innovation from kindergartens principals point of view in Amman, Journal of Psychological and Educational Sciences - Bahrain, 14(3), 445-470.

Boudrias, J. S., Gaudreau, P., Savoie, A., \& Morin, A. J. (2009). Employee empowerment from Managerial practices to employees behavioral empowerment. Leadership \& Organization Development Journal, 30(7), 625-638. http://dx.doi.org/10.1108/01437730910991646

Boundrias, J. G \& Patrick, S .A \& Alexander, J.S) 2009)Employee empowerment from Managerial practices to employees behavioral empowerment. Leadership organization Development journal, 30(7), 625-638. http://dx.doi.org/10.1108/01437730910991646 
Ebdah, A, Mohammed \& Jagbeer, (2008). Innovation degree in administrative behavior for secondary and elementary school principals from teacher's point of view belonging to the Directorate of Education in Salt. Journal of Culture and Development - Egypt, S 8, 24, 2-39.

Gill, A., Fitzgerald, S., Bhutani, S., Mand, H., \& Sharma, S. (2010). The relationship between transformation leadership and employee desire for empowerment. International Journal of $\begin{array}{llll}\text { Contemporary Hospitality 263-273. } & \text { 26nagement, }\end{array}$ http://dx.doi.org/10.1108/09596111011018223

Hamouri, A., \& Saud, R. (2010). The degree of career empowerment for academic leaders in official Jordanian universities and their relationship to Achievement motivation they have. Mutah Journal for Research and Studies, a series of Human and Social Sciences, 15(7), 97.

Hareem, H. (1997). Organizational behavior: Persons behavior in organizations, Dar Zahran for Publishing and Distribution, Amman, Jordan, 463-484.

Krieitner, R., \& Kinick, A. (1992). Organizational Behavior (2nd ed.). Home wood. 111: IRWIN: 430-431.

Lau, W. K. (2010). Empowerment of non - academic personnel in higher education: Exploring association perceived organizational support for innovation and organization Trust. PH.D. Thesis of University of Iowa, Iowa city, the Graduate College of University of Iowa

Melhem, S. (2009). Empowerment as contemporary administrative concept, the first edition, the Arab Organization for Administrative Development, Cairo.

Memar, S, Bin Darwish (2003). Towards the development of innovative work. Umm Al-Qura University Journal, 15(2), 156-178.

Mohammed, M. A., \& Morsi, O. M. (2012). Organizational culture and its relationship to administrative innovation to administrative leadership at Assiut University, Faculty of Education, the scientific journal, Assiut University, Egypt.

Omari, Mohammed bin Saaeed (2011). Career Empowerment and organizational commitment to the academic leaders at King Saud University, King Saud University Journal, Management Sciences (1), Riyadh, AD 23, pp. 60-97.

Qudah, Sh., \& Melhem, Y. (2011). Impact of information and information Technology on Empowerment of Employees Private School Sector in Northern Region in Jordan. Journal of Emerging Trends in Economics and Management Sciences (JETEMS), 2(1), 40-48.

Robey, D. (1991). Designing Organization (3rd ed.). Home wood, 111, IRWIN, Evan, op. city, 424.

Seung, \& Bum, Y, C. (2009). Employee empowerment and team performance: Autonomy responsibility information and creativity: Emerald Group Publishing, 15(5), 289-301. 
Shousha, A, Ali (2011). the effect of employees empowering to innovative behavior, practical study on the staff working in informational technology in Mansoura University. Arab Journal of Commercial Studies, 35(1), 1-28.

Ta'ani, H, Ahmed (2011). the degree of administrative empowerment at public schools in Karak, Jordan. Journal of Education, 25(98), 201.

Watanabe, M. (2011). Interpretive policy Analysis on Enhancing education Equity and Empowerment for girls in Rural India, Dissertation, United States/ Arizona

White, P. (1992). Teacher Empowerment under school site autonomy Educational Evaluation and policy analysis, 14(10), 69- 82. http://dx.doi.org/10.3102/01623737014001069

\section{Copyright Disclaimer}

Copyright reserved by the authors.

This article is an open-access article distributed under the terms and conditions of the Creative Commons Attribution license (http://creativecommons.org/licenses/by/3.0/). 